\title{
Correction to: Coastal food: a composite method for past events characterisation providing insights in past, present and future hazards-joining historical, statistical and modelling approaches
}

\section{Déborah Idier $^{1}$ - Jérémy Rohmer ${ }^{1} \cdot$ Rodrigo Pedreros $^{1}$. Sylvestre Le Roy ${ }^{2}$.} Jérome Lambert ${ }^{1}$. Jessie Louisor ${ }^{1}$. Gonéri Le Cozannet ${ }^{1}$. Erwan Le Cornec ${ }^{3}$

Published online: 9 March 2020

(c) Springer Nature B.V. 2020

\section{Correction to: Natural Hazards https://doi.org/10.1007/s11069-020-03882-4}

The original article was published with erroneous placement of its figures. Following reports by the author group concerning the errors, the article was granted an update + correction to show the desired rendering of the work. This correction stands to support the update, and the original article has been corrected.

The original article can be found online at https://doi.org/10.1007/s11069-020-03882-4.

Déborah Idier

d.idier@brgm.fr

1 BRGM, 3 av. C. Guillemin, 45060 Orléans Cédex, France

2 BRGM, 2 Rue de Jouanet, 35700 Rennes, France

3 GEOS-AEL, 12 Rue Maréchal Foch, 56410 Etel, France 